\title{
Impact of sociodemographic factors on cognitive function in school-aged HIV-infected Nigerian children
}

This article was published in the following Dove Press journal:

HIVIAIDS - Research and Palliative Care

13 July 2013

Number of times this article has been viewed

\author{
Gbemisola O Boyede ${ }^{1,2}$ \\ Foluso EA Lesi \\ Veronica C Ezeaka ${ }^{2}$ \\ Charles S Umeh ${ }^{3}$ \\ 'Division of Developmental \\ Paediatrics, School of Child and \\ Adolescent Health, Red Cross \\ War Memorial Children's Hospital, \\ University of Cape Town, Cape Town, \\ South Africa; ${ }^{2}$ Department \\ of Paediatrics, ${ }^{3}$ Clinical Psychology \\ Unit, Department of Psychiatry, \\ Lagos University Teaching Hospital, \\ Lagos, Nigeria
}

Background: In this study, we sought to evaluate the influence of sociodemographic factors, ie, age, sex, socioeconomic status, maternal education, and human immunodeficiency virus (HIV) status, on cognitive performance in school-aged HIV-infected Nigerian children.

Methods: Sixty-nine HIV-positive children aged 6-15 years were matched with 69 HIV-negative control children for age and sex. The children were subdivided for the purpose of analysis into two cognitive developmental stages using Piaget's staging, ie, the concrete operational stage (6-11 years) and the formal operational stage (12-15 years). All participants underwent cognitive assessment using Raven's Standard Progressive Matrices (RPM). Sociodemographic data for the study participants, ie, age, sex, socioeconomic status, and level of maternal education, were obtained using a study proforma. Logistic regression analyses were used to determine associations of HIV status and sociodemographic characteristics with RPM cognitive scores.

Results: The overall mean RPM score for the HIV-positive children was $18.2 \pm 9.8$ (range 8.0-47.0) which was significantly lower than the score of $27.2 \pm 13.8$ (range 8.0-52.0) for the HIV-negative children $(P<0.001)$. On RPM grading, 56.5\% of the HIV-positive children had cognitive performance at below average to intellectually defective range. Below average RPM scores were found to be significantly associated with younger age (6-11 years), positive HIV status, lower socioeconomic status, and low level of maternal education.

Conclusion: Younger age, poor socioeconomic status, and low level of maternal education were factors apart from HIV infection that were significantly associated with low cognitive function in school-aged HIV-infected Nigerian children.

Keywords: pediatric human immunodeficiency virus, cognitive assessment, school-aged children, Raven's Progressive Matrices, Nigeria

\section{Introduction}

Human immunodeficiency virus (HIV) infection and acquired immunodeficiency syndrome (AIDS) is a global pandemic. Pediatric HIV/AIDS is a significant cause of childhood morbidity and mortality in Africa. ${ }^{1}$ In the 2010 AIDS epidemic update, the Joint United Nations Programme on HIV/AIDS, reported that at the end of 2009, 2.5 million children were living with HIV worldwide and $91 \%$ of this population live in Sub-Saharan Africa. ${ }^{2}$ Nigeria has one of the highest burdens of mother-to-child transmission of HIV/AIDS in the world. ${ }^{3}$

From the recognition of pediatric HIV infection in the early $1980 \mathrm{~s}$, delayed neurodevelopment and neurocognitive impairment have been recognized as complications. ${ }^{4}$ HIV-infected children with these complications present with both neurologic and neuropsychologic derangements manifesting as motor and
Correspondence: Gbemisola Boyede Division of Developmental Paediatrics, School and Child and Adolescent Health, Red Cross War Memorial Children's Hospital, University of Cape Town, Klipfontein Road, Rondebosch 7700

Cape Town, South Africa

Tel +27 79 II 50729

Email gbemisola.boyede@uct.ac.za 
cognitive deficits. Most of the studies in infants and young children in the developed world were consistent in their finding of delayed neurodevelopment among HIV-infected children. ${ }^{5-11}$ Among African infants and preschool-aged children, similar findings have been documented. ${ }^{12-16}$ However, advances in the medical treatment of children with HIV, including the development and use of combination antiretroviral therapies and supportive medications, not only have prolonged survival but also have promoted growth and development and have improved quality of life. ${ }^{9}$ Many HIVinfected children are now surviving into adolescence and adulthood. Despite the improved survival with antiretroviral therapy, some studies in school-aged children seem to show persistence of neurodevelopmental delay into school age, leading to poor cognitive functioning and academic performance. ${ }^{17-20}$

Other studies have shown that there are other clinical, social, economic, and environmental factors that influence cognitive function of infected children in addition to HIV status. ${ }^{21-23}$ In the United States, Smith et al ${ }^{21}$ showed that children aged 3-7 years with HIV infection and Centre for Disease Control and Prevention HIV staging Class C (most severe category) status scored significantly lower in all domains of cognitive development using the McCarthy scales across all time points than did those who were HIVinfected without an AIDS-defining illness and those who were exposed to HIV but not infected. Factors that were associated consistently and significantly with lower mean scores were HIV status, number of times an examination had been completed previously, primary language, maternal education, and sex. Boivin et $\mathrm{al}^{14}$ documented developmental impairment in both asymptomatic HIV-infected children and HIV-exposed but uninfected children compared with control children in Zaire. The authors inferred that there may be an environmental component compounding the developmental delay as a result of the presence of HIV in the central nervous system.

Studies of cognitive functioning in school-aged HIVinfected children in Africa are few. One published study of school-aged Ugandan children by Bagenda et al found no difference in cognitive performance between HIVinfected children who were highly active antiretroviral therapy (HAART)-naïve and HIV-negative controls. ${ }^{23}$ Many African children now survive up to school age due to free antiretroviral therapy in many countries, including Nigeria. Currently, neurodevelopmental assessments are not part of the routine care of HIV-infected children in
Nigeria. Studies in developed countries have shown that additional factors, including socioeconomic status and level of maternal education, influence cognition in HIV-infected children. This infers that use of HAART alone perhaps is not sufficient to manage the neurodevelopmental delays of HIV without other interventions to address the associated factors. The specific sociodemographic factors in our local setting must be identified to be able to take a holistic approach to management. Therefore, this study was designed to evaluate the effect of HIV status, age, sex, level of maternal education, and socioeconomic status on cognitive function in a group of HIV-infected school-aged Nigerian children using Raven's Standard Progressive Matrices (RPM).

\section{Materials and methods Study location}

This was a cross-sectional study conducted between November 2009 and April 2010 at Lagos University Teaching Hospital (LUTH), Lagos State, Nigeria. LUTH is a 750-bed tertiary center providing health care to the inhabitants of Lagos and neighboring states. Children younger than 18 years have health care provided through the department of pediatrics at LUTH.

There is a dedicated pediatric HIV clinic for care of HIVinfected children. The total number of HIV-positive children attending the pediatric HIV clinic at the end of 2009 was 566, of whom 223 were aged 6-15 years. The latter group had 174 children on HAART while 49 were still HAART-naive. The HIV-infected children were being managed according to national guidelines for pediatric HIV/AIDS treatment and care based on the clinical and immunologic stage of their disease. ${ }^{3}$ HIV infection was diagnosed using a positive enzyme-linked immunosorbent assay test, which was confirmed by Western blotting. ${ }^{3}$ HIV-infected children aged younger than 18 months had their diagnosis confirmed by HIV DNA polymerase chain reaction tests.

\section{Study participants}

School-aged HIV-infected children (6-15 years) accessing care from the pediatric HIV clinic at LUTH constituted the study population. The HIV-negative controls were drawn from children in the same age range being followed up at the pediatric outpatient clinics. Parents of the HIV-negative controls were offered provider-initiated counseling and testing of their wards. The children of parents/guardians who consented were tested for HIV using the enzyme-linked immunosorbent assay method. Routine pretest and post-test 
counseling is provided for all individuals being tested at the pediatric HIV clinic.

Inclusion criteria were: confirmed HIV infection; age 6-15 years inclusive; HIV status disclosure (partially or fully) to the child by the parents and/or counselors; and signed informed consent by the parents/guardians as well as the verbal/written assent of the children. The inclusion criteria were the same for the HIV-negative children except for HIV status, which was negative. Exclusion criteria were acute illness and/or hospital admission at the time of cognitive testing; a chronic neurologic disorder such as epilepsy, cerebral palsy; and inability to perform the RPM cognitive test for whatever reason. One hundred and thirty-eight children comprising $69 \mathrm{HIV}$-positive and $69 \mathrm{HIV}$-negative participants were recruited into the study. Thirty-nine of the HIV-positive participants (56\%) were on HAART. The study participants were subdivided for purposes of analysis into two cognitive developmental stages using Piaget's staging, ie, the concrete operational stage (6-11 years) and the formal operational stage (12-15 years).

\section{The instrument}

The RPM is a widely used nonverbal test of general intelligence that appraises visuospatial reasoning, abstract thinking, deductive reasoning, and general intelligence. ${ }^{24}$ The RPM consists of 60 problems divided into five subsets of 12. Each person's total score is the total number he/she answered correctly. In RPM, a person is shown a matrix of patterns with one pattern missing. The person must figure out the rules governing the patterns and then use these rules to pick the item that best fills in the missing pattern. Each individual's score is graded in terms of where the score falls on percentiles for his/her age group normative scores as recommended in the test manual. ${ }^{24}$ The scores were classified based on percentile scores as follows: grade I, "intellectually superior" (scores at or above the 95th percentile); grade II, "definitely above average in intellectual capacity" (scores at or above the 75th percentile); grade III, "intellectually average" (scores between the 25 th and the 75 th percentiles); grade IV, "definitely below average in intellectual capacity" (scores at or below the 25 th percentile); and grade V, "intellectually defective" (scores at or below the 5th percentile).

The test is designed to minimize the influence of culture by relying on nonverbal problems that require abstract reasoning and do not require knowledge of a particular culture. RPM has been validated for use for Nigerian children. ${ }^{25}$

\section{Procedures and data collection}

School-aged HIV-positive and HIV-negative children seen at the pediatric HIV and outpatient clinics who satisfied the inclusion and exclusion criteria were recruited into the study until the estimated sample size was attained. After obtaining informed consents/assents from the parents/ children, the researcher administered the study proforma. The proforma consisted of five sections: sociodemographic data, medical history, neurologic symptoms, neurologic examination, and RPM cognitive tests. The sociodemographic data obtained were age, sex, educational level, socioeconomic status, primary caregiver, and level of maternal education. The socioeconomic status of the families of the subjects was computed using the method recommended by Oyedeji in his study of the socioeconomic and cultural background of children hospitalized in Ilesa, Nigeria. ${ }^{26}$

\section{Data analyses}

Data were entered, validated, and analyzed using the Statistical Package for the Social Sciences version 17.0 software (SPSS Inc, Chicago, IL, USA). ${ }^{27}$ Simple and multiple logistic regression analyses were performed to determine associations of HIV status and sociodemographic characteristics (independent variables) with RPM scores (dependent variable). The outcome variable, ie, the RPM score, was dichotomized to below average RPM scores and average and above average scores. Strengths of association were determined by odds ratio (OR) and 95\% confidence interval. A $P$-value less than 0.05 was accepted as being statistically significant (two-tailed analysis).

\section{Ethical approval}

The study was approved by the LUTH research and ethics committee before commencement of the study. Written informed consents were obtained from the parents/guardians and verbal/written assents were obtained from the participants. The children were informed of their scores and parents/ caregivers were counseled on the need for follow-up care.

\section{Results}

The mean age of the HIV-positive children was $9.86 \pm 2.48$ years and was comparable with the $9.64 \pm 2.42$ years for their HIVnegative counterparts. Table 1 shows the sociodemographic characteristics of the HIV-positive and HIV-negative study participants. There were significantly more HIV-negative 
Table I Sociodemographic characteristics of HIV-positive and HIV-negative subjects

\begin{tabular}{|c|c|c|c|}
\hline Characteristics & $\begin{array}{l}\text { HIV-positive } \\
n=69\end{array}$ & $\begin{array}{l}\text { HIV-negative } \\
n=69\end{array}$ & $P$-value \\
\hline Age (years) & $9.86 \pm 2.48$ & $9.64 \pm 2.42$ & 0.61 \\
\hline $6-11$ & $55(80 \%)$ & $55(80 \%)$ & 1.00 \\
\hline $12-15$ & $14(20 \%)$ & $14(20 \%)$ & \\
\hline \multicolumn{4}{|l|}{ Sex } \\
\hline Male & 34 (49.3\%) & $33(47.8 \%)$ & 0.87 \\
\hline Female & 35 (50.7\%) & $36(52.2 \%)$ & \\
\hline \multicolumn{4}{|l|}{ Level of education } \\
\hline Nursery & $4(5.8 \%)$ & $\mathrm{I}(\mathrm{I} .5 \%)$ & 0.48 \\
\hline Primary & $52(75.4 \%)$ & $5 \mathrm{I}(73.9 \%)$ & \\
\hline Junior secondary & $10(14.5 \%)$ & $12(17.4 \%)$ & \\
\hline Senior secondary & $3(4.3 \%)$ & $5(7.2 \%)$ & \\
\hline \multicolumn{4}{|l|}{ Socioeconomic class } \\
\hline Upper & $26(37.7 \%)$ & $45(65.2 \%)$ & $0.01 *$ \\
\hline Middle & $28(40.6 \%)$ & $16(23.2 \%)$ & \\
\hline Lower & $15(21.7 \%)$ & $8(11.6 \%)$ & \\
\hline \multicolumn{4}{|l|}{ Primary caregiver } \\
\hline Mother & $53(76.8 \%)$ & $51(73.9 \%)$ & 0.69 \\
\hline Others & $16(23.2 \%)$ & $18(26.1 \%)$ & \\
\hline \multicolumn{4}{|c|}{ Maternal level of education } \\
\hline Tertiary & $15(21.7 \%)$ & $39(56.5 \%)$ & $0.00 I^{*}$ \\
\hline Secondary & $35(50.7 \%)$ & $21(30.4 \%)$ & \\
\hline Primary & $16(23.3 \%)$ & $7(10.1 \%)$ & \\
\hline None & $3(4.3 \%)$ & $2(2.9 \%)$ & \\
\hline \multicolumn{4}{|l|}{ Maternal HIV status } \\
\hline Positive & $53(76.8 \%)$ & $0(0.0 \%)$ & $0.00 I^{*}$ \\
\hline Negative & $8(11.6 \%)$ & $40(58.0 \%)$ & \\
\hline Unknown & 8 (11.6\%) & 29 (42.0\%) & \\
\hline
\end{tabular}

Note: $* P$-value significant.

Abbreviations: HIV, human immunodeficiency virus; RPM, Raven's Standard Progressive Matrices.

children in the upper stratum and more HIV-positive children in the lower stratum $(P=0.01)$. Also, in terms of level of maternal education, significantly more mothers $(56.5 \%)$ of the HIV-negative children had tertiary education compared with mothers $(21.7 \%)$ of the HIV-positive children $(P=0.001)$.

\section{RPM cognitive scores for HIV-positive and HIV-negative subjects}

The overall mean RPM score for the HIV-positive children was $18.2 \pm 9.8$ (range 8.0-47.0) which was significantly lower than the mean score of $27.2 \pm 13.8$ (range 8.0-52.0) for the HIV-negative children $(P=0.001)$. On subgroup analysis, in the age group 6-11 years, the mean RPM score of the HIV-positive participants was $15.5 \pm 6.9$, which was significantly higher than the mean score of $24.9 \pm 13.1$ for the HIV-negative participants $(P=0.001)$. In the age group 12-15 years, the mean RPM score for the HIV-positive children was $28.8 \pm 12.6$, which was lower than the score of $36.2 \pm 13.3$ for the HIV-negative control children. However, the difference failed to reach statistical significance $(P=0.06)$.

\section{RPM grading of HIV-positive and HIV- negative subjects}

The distribution of the study participants by RPM grading is shown in Table 2. About two-thirds of the HIVnegative children had at least average and above RPM scores compared with less than half of the HIV-positive subjects with same grade scores. Conversely, more than half of the HIV-positive children had RPM scores below average and lower grades compared with one-third of the HIV-negative children with similar grades. This difference in RPM grading between the HIV-positive and HIV-negative participants was statistically significant $\left(\chi^{2}=7.50, P=0.006\right)$.

\section{Association of RPM scores with HIV status and sociodemographic characteristics}

The RPM scores on regression analyses were associated with HIV status, age, socioeconomic status, and level of maternal education, as shown in Table 3 . With respect to HIV status, the HIV-positive children were 3.5 times more likely to have below average RPM scores compared with HIV-negative children (OR 3.54; CI 1.62-7.12). In terms of age, the younger children (6-11 years) were seven times more likely to have below average scores than the older children (12-15 years, OR 7.00; CI 3.03-16.67). As regards, socioeconomic status, children from the lower strata were three times more likely to have lower mean RPM scores compared with children from the upper strata (OR 3.08; CI 1.09-10.58). In addition, children of mothers with primary or no education were almost three times more likely to

Table 2 RPM grading of HIV-positive and HIV-negative children

\begin{tabular}{llll}
\hline RPM grade & $\begin{array}{l}\text { HIV-positive } \\
\text { n (\%) }\end{array}$ & $\begin{array}{l}\text { HIV-negative } \\
\text { n (\%) }\end{array}$ & $\begin{array}{l}\text { Total } \\
\text { n (\%) }\end{array}$ \\
\hline $\begin{array}{l}\text { Grade I (superior) } \\
\text { Grade 2 }\end{array}$ & I (I.4\%) & $5(7.2 \%)$ & $6(4.3 \%)$ \\
(above average) & I (I.4\%) & $15(21.7 \%)$ & $16(1.6 \%)$ \\
$\begin{array}{l}\text { Grade 3 (average) } \\
\text { Grade 4 }\end{array}$ & $28(40.6 \%)$ & $26(37.7 \%)$ & $54(39.1 \%)$ \\
$\begin{array}{l}\text { (below average) } \\
\begin{array}{l}\text { Grade 5 } \\
\text { (intellectual deficit) }\end{array}\end{array}$ & $27(39.1 \%)$ & $16(23.2 \%)$ & $43(31.2 \%)$ \\
\hline
\end{tabular}

Abbreviations: HIV, human immunodeficiency virus; RPM, Raven's Standard Progressive Matrices. 
Table 3 Simple logistic regression of below average RPM scores on HIV status and sociodemographic characteristics

\begin{tabular}{|c|c|c|c|c|c|c|c|}
\hline \multirow[t]{2}{*}{ Characteristics } & \multicolumn{2}{|l|}{ RPM scores } & \multirow[t]{2}{*}{ OR } & \multicolumn{2}{|l|}{$95 \% \mathrm{Cl}$} & \multirow[t]{2}{*}{$\beta$} & \multirow[t]{2}{*}{ SE } \\
\hline & $\begin{array}{l}\text { Below average } \\
\text { n (\%) }\end{array}$ & $\begin{array}{l}\text { Average and above } \\
\text { n (\%) }\end{array}$ & & Lower & Upper & & \\
\hline \multicolumn{8}{|l|}{ Age group } \\
\hline 6-11 years & 77 (70.0\%) & $33(30.0 \%)$ & $7.00 *$ & 3.03 & 16.67 & 1.75 & 0.45 \\
\hline $12-15$ years & 7 (25.0\%) & $21(75.0 \%)$ & 1.00 & & & & \\
\hline \multicolumn{8}{|l|}{ HIV status } \\
\hline Positive & 52 (75.4\%) & $17(24.6 \%)$ & $3.54 *$ & 1.62 & 7.12 & 1.26 & 0.37 \\
\hline Negative & 32 (46.4\%) & 37 (53.5\%) & 1.00 & & & & \\
\hline \multicolumn{8}{|l|}{ Sex } \\
\hline Male & $4 \mathrm{I}(6 \mathrm{I} .2 \%)$ & $26(38.8 \%)$ & 1.03 & 0.49 & 2.16 & 0.03 & 0.35 \\
\hline Female & $43(60.6 \%)$ & $28(39.4 \%)$ & 1.00 & & & & \\
\hline \multicolumn{8}{|l|}{ SES } \\
\hline Middle & $33(24.6 \%)$ & II (26.I\%) & $3.27^{*}$ & 1.33 & 8.14 & 1.18 & 0.42 \\
\hline Upper & 34 (58.3\%) & 37 (4I.7\%) & 1.00 & & & & \\
\hline \multicolumn{8}{|l|}{ SES } \\
\hline Lower & $17(24.6 \%)$ & $6(26.1 \%)$ & $3.08 *$ & 1.09 & 10.58 & 1.13 & 0.53 \\
\hline Upper & 34 (58.3\%) & $37(41.7 \%)$ & 1.00 & & & & \\
\hline \multicolumn{8}{|l|}{ Maternal education } \\
\hline Primary/none & $22(78.6 \%)$ & $6(21.4 \%)$ & $2.84 *$ & 1.14 & 9.18 & 1.10 & 0.50 \\
\hline Secondary/tertiary & $62(56.4 \%)$ & 48 (43.6\%) & 1.00 & & & & \\
\hline
\end{tabular}

Note: *Significant $\beta=$ regression coefficient.

Abbreviations: HIV, human immunodeficiency virus; RPM, Raven's Standard Progressive Matrices; OR, odds ratio; SE, standard error; Cl, confidence interval; SES, socioeconomic status.

have below average RPM scores compared with children of mothers with secondary or tertiary education. However, multiple stepwise logistic regression analyses showed significant associations of below average RPM scores only with positive HIV status and younger age (6-11 years) group (Table 4).

Table 4 Multiple logistic regression of below average RPM scores on HIV status and sociodemographic characteristics

\begin{tabular}{|c|c|c|c|c|c|}
\hline \multirow[t]{2}{*}{ Characteristics } & \multirow{2}{*}{$\begin{array}{l}\text { Odds } \\
\text { ratio }\end{array}$} & \multicolumn{2}{|l|}{$95 \% \mathrm{Cl}$} & \multirow[t]{2}{*}{$\beta$} & \multirow[t]{2}{*}{ SE } \\
\hline & & Lower & Upper & & \\
\hline Constant & - & - & - & -2.24 & 0.57 \\
\hline \multicolumn{6}{|l|}{ Age, years } \\
\hline $6-11$ & $8.24 *$ & 2.94 & 23.12 & 2.11 & 0.53 \\
\hline $12-15$ & 1.00 & & & & \\
\hline \multicolumn{6}{|l|}{ HIV status } \\
\hline Positive & $2.99 *$ & 1.31 & 6.81 & 1.09 & 0.42 \\
\hline Negative & 1.00 & & & & \\
\hline \multicolumn{6}{|l|}{ Socioeconomic status } \\
\hline Middle & 2.59 & 1.00 & 6.73 & 0.95 & 0.49 \\
\hline Upper & 1.00 & & & & \\
\hline \multicolumn{6}{|l|}{ Socioeconomic status } \\
\hline Lower & 1.93 & 1.22 & 20.89 & 1.62 & 0.72 \\
\hline Upper & 1.00 & & & & \\
\hline \multicolumn{6}{|l|}{ Maternal education } \\
\hline Secondary/tertiary & 2.58 & 0.49 & 7.60 & 0.66 & 0.70 \\
\hline Primary/none & 1.00 & & & & \\
\hline
\end{tabular}

Note: *Significant $\beta=$ regression coefficient.

Abbreviations: HIV, human immunodeficiency virus; RPM, Raven's Standard Progressive Matrices; SE, standard error; $\mathrm{Cl}$, confidence interval.

\section{Discussion}

The finding that RPM cognitive scores for HIV-positive children are lower than those of HIV-negative children is similar to other reports for school-aged HIV-positive children in the US and Greece. ${ }^{18,19}$ In the present study, $56.5 \%$ of the HIV-positive children had cognitive performance at below average to intellectual deficit range, which is comparable with the $56 \%$ reported by Papola et al ${ }^{18}$ among school-aged HIV-infected children in the US. The latter study had one of the largest samples of school-aged HIV-infected children studied in the US. The American children were clinically stable at the time of their assessments and the majority $(82 \%)$ were on antiretroviral therapy. The age range of the children (5-14 years) was also comparable with the 6-15 years in the present study. ${ }^{19}$

However, the finding of lower cognitive scores for HIVpositive children in the current study is at variance with other studies in Uganda and France that found no difference in the cognitive performance of HIV-infected children and HIV-negative controls. ${ }^{20,23}$ In Uganda, Bagenda et al found no statistically significant difference in cognitive scores for school-aged HIV-positive and HIV-negative control children using the Kaufmann Assessment Battery for Children, which has nonverbal subsections similar to the RPM. ${ }^{23}$ However, the HIV-infected children in the Ugandan study had never been on antiretroviral therapy and were long-term survivors 
of a cohort of perinatally HIV-infected children. This is in contrast with the present study, which included HIV-infected children on HAART. It is possible that the Ugandan children had a more clinically stable form of HIV disease with cognitive performance in the near-normal range compared with their HIV-negative counterparts. It is known that the manifestations of HIV-associated encephalopathy are variable in infected children. However, it is not clear why some infected children develop a more severe form of encephalopathy than others. Also, in contrast with the present study, Tardieu et $\mathrm{al}^{20}$ reported that HIV-infected children in France had cognitive function in the normal range. All the children in the French study were ambulatory and neurologically stable, with the majority on antiretroviral therapy, so are comparable with the HIV-infected children in the current study. However, the French children were not compared with a control group.

Factors found in the present study to be associated with below average RPM scores were positive HIV status, younger age (6-11 years), lower socioeconomic status, and primary or no maternal education. The association of below average RPM scores with HIV status was expected in view of the already documented effect of HIV on the central nervous system. ${ }^{4}$ RPM scores have been known to vary with age. ${ }^{28}$ Raven, in an analysis of the 1979 RPM normative study in the UK, found that age accounted for $46 \%$ of the variance seen in RPM scores, while socioeconomic status accounted for $8.9 \% .{ }^{28}$ Children at a lower developmental stage would have lower raw cognitive scores than older children, hence the need to interpret a child's individual score based on the average score obtained from children of the same age or developmental stage. ${ }^{24}$

Socioeconomic status is also a well known determinant of cognitive functioning. Coscia et al found a lower level of cognitive functioning among HIV-infected children of lower socioeconomic status mediated via the home environment. ${ }^{22}$ Home environment and parent-child interaction may explain some of the differences in cognitive function between children of lower and higher socioeconomic status. ${ }^{29}$ It is speculated that children from families of low socioeconomic status are more likely to live in less stimulating and supportive home environments. ${ }^{29}$ Stimulation provides both direct and indirect learning opportunities and serves as a motivational basis for continued learning. It has been argued that children of lower socioeconomic status lack cognitively stimulating materials and experiences, which limits their cognitive growth. ${ }^{30}$ Stimulating materials and experiences mediate the relationship between socioeconomic status or family income and children's intellectual and academic achievement from infancy to adolescence. ${ }^{31}$
A significant association between a lower level of maternal education and below average RPM score has also been reported by Smith et $\mathrm{al}^{21}$ and other workers. ${ }^{32,33}$ It is possible that better educated mothers provide more cognitively stimulating experiences for their children than their counterparts with less education, which has been shown to have a positive impact on cognitive development. ${ }^{30}$ In addition, the effect of maternal education on a child's cognitive function may be an indirect effect of socioeconomic status.

However, after controlling for possible confounders with multiple logistic regression analyses, positive HIV status and younger age were the main factors significantly associated with below average RPM scores in our group of schoolaged Nigerian children with HIV infection. This implies the need for neuropsychologic evaluation of HIV-infected schoolaged children, especially those in the younger age group of 6-11 years. Appropriate interventions and therapies should also be instituted early for children with cognitive impairment.

This study has some limitations. In particular, it was a cross-sectional study with just one cognitive assessment. A longitudinal prospective cohort study with multiple interval assessments would have given more information about cognitive deficits. The effect of other birth-related events could be controlled for in a long-term follow-up study. Furthermore, different domains of development were not assessed. This was because of the need to perform a brief cognitive test that could be done on an outpatient basis. The current study is a preliminary one intended to inspire more indepth research into cognitive functioning in HIV-infected school-aged children.

\section{Conclusion}

RPM scores in this group of clinically and neurologically stable school-aged HIV-infected Nigerian children aged 6-11 years were significantly lower than those of HIV-negative controls matched for age and sex. Below average RPM scores were strongly associated with positive HIV status, younger age, lower socioeconomic status, and primary/no maternal education. We recommend that HIV-infected Nigerian children of school age should have neurodevelopmental evaluation as part of their standard care. Early detection of cognitive deficits will lead to prompt intervention which will improve the long-term outcomes for affected children. However, there is still a need for more research, especially longitudinal cohort studies in HIV-infected Nigerian children incorporating multiple interval assessments to validate the findings of this preliminary study. 


\section{Acknowledgment}

We thank all the parents and children attending the Pediatric HIV and Pediatric Outpatient clinics who participated in the study. We also acknowledge the laboratory and data room staff of the Aids Prevention in Nigeria clinic for their assistance during the course of the project.

\section{Author contributions}

GOB conceived and designed the study, performed data collection, and analysis. FEAL and VCE contributed to the study design and data analysis. CSU provided the cognitive assessment instrument and contributed to evaluation of data generated by use of this tool. All authors contributed to review of the draft manuscript and approved the final version for publication.

\section{Disclosure}

The authors report no conflicts of interest in this study.

\section{References}

1. Tindyebwa D, Kayita J, Musoke P, et al, editors. Handbook on Paediatric AIDS in Africa. Kampala, Uganda: African Network for the Care of Children Affected by AIDS; 2006.

2. Joint United Nation Programme on HIV/AIDS. UNAIDS report on the global AIDS epidemic 2010. Available from: http://www. unaids.org/en/media/unaids/contentassets/documents/unaidspublication/2010/20101123_globalreport_en.pdf. Accessed October 12, 2012.

3. Federal Ministry of Health. National Guidelines for Paediatric HIV and AIDS Treatment and Care. Federal Ministry of Health, HIV and AIDS Division: Abuja, Nigeria; 2007.

4. Wolters P, Brouwers P. Evaluation of neurodevelopmental deficits in children with HIV infection. In: Gendelman HE, Lipton SA Epstein L, Swindells S, editors. The Neurology of AIDS. New York, NY: Chapman \& Hall; 1999.

5. Chase C, Ware J, Hittelman J, et al. Early cognitive and motor development among infants born to women infected with human immunodeficiency virus: Women and Infants Transmission Study Group. Pediatrics. 2000;106:E25.

6. Cooper E, Hanson C, Diaz C, et al. Encephalopathy and progression of human immunodeficiency virus disease in a cohort of children with perinatally acquired human immunodeficiency virus infection: Women and Infants Transmission Study Group. J Pediatr. 1998;132: 808-812

7. Mellins C, Levenson R, Zawadzki R, Kairam R, Weston M. Effects of pediatric HIV infection and prenatal drug exposure on mental and psychomotor development. J Pediatr Psychol. 1994;19:617-628.

8. Wolters P, Brouwers P, Moss H, Pizzo P. Differential receptive and expressive language functioning of children with symptomatic HIV disease and relation to CT scan brain abnormalities. Pediatrics. 1995;95:112-119.

9. Millana-Cuevas L, Portellano J, Martinez-Arias R. Neuropsychological impairment in human immunodeficiency virus-positive children. Rev Neurol. 2007;44:366-374.

10. Diamond G, Gurdin P, Wiznia A, Belman A, Rubinstein A, Cohen H. Effects of congenital HIV infection on neurodevelopmental status of babies in foster care. Dev Med Child Neurol. 1990;32:999-1005.
11. Levenson R, Mellins C, Zawadzki R, Kairam R, Stein Z. Cognitive assessment of human immunodeficiency virus-exposed children. Am J Dis Child. 1992;146:1479-1483.

12. Msellati P, Lepage P, Hitimana D, Van Goethem C, Van de Perre P, Dabis F. Neurodevelopmental testing of children born to human immunodeficiency virus type 1 seropositive and seronegative mothers: a prospective cohort study in Kigali, Rwanda. Pediatrics. 1993;92: 843-848.

13. Drotar D, Olness K, Wiznitzer M, et al. Neurodevelopmental outcomes of Ugandan infants with human immunodeficiency virus type 1 infection. Pediatrics. 1997;100:e5.

14. Boivin M, Green S, Davies A, Giordani B, Mokili J, Cutting W. A preliminary evaluation of the cognitive and motor effects of pediatric HIV infection in Zairian children. Health Psychol. 1995;14:13-21.

15. McGrath N, Bellinger D, Robins J, Msamanga GI, Tronick E, Fawzi W. Effect of maternal multivitamin supplementation on the mental and psychomotor development of children who are born to HIV-1-infected mothers in Tanzania. Pediatrics. 2006;117:e216.

16. Van Rie A, Mupuala A, Dow A. Impact of the HIV/AIDS epidemic on the neurodevelopment of preschool-aged children in Kinshasa, Democratic Republic of the Congo. Pediatrics. 2008;122: e123-e128.

17. Blanchette N, Smith M, King S, Fernandea-Penney A, Read S. Cognitive development in school-age children with vertically transmitted HIV infection. Dev Neuropsychol. 2002;2:223-241.

18. Papola P, Alvarez M, Cohen H. Developmental and service needs of school children with HIV. Pediatrics. 1994;94:914-918.

19. Bertou G, Thomaidis L, Spoulou V, Theodoridou M. Cognitive and behavioral abilities of children with HIV infection in Greece. Pediatrics. 2008;121:S100.

20. Tardieu M, Mayaux M, Seibel N, et al. Cognitive assessment of school-age children infected with maternally transmitted human immunodeficiency virus type 1. J Pediatr. 1995;126:375-379.

21. Smith R, Malee K, Leighty R, et al; Women and Infants Transmission Study Group. Effects of perinatal HIV infection and associated risk factors on cognitive development among young children. Pediatrics. 2006;117:851-862.

22. Coscia J, Christensen B, Henry R, Wallston K, Radcliffe J. Effects of home environment, socioeconomic status, and health status on cognitive functioning in children with HIV-1 infection. J Pediatr Psychol. 2001;26: 321-329.

23. Bagenda D, Nassali A, Kalyesubula I, et al. Health, neurologic, and cognitive status of HIV-infected, long-surviving, and antiretroviral-naive Ugandan children. Pediatrics. 2006;117:729-740.

24. Raven J. Standard Progressive Matrices. London, UK: HK Lewis; 1958.

25. Ogunlade O. The predictive validity of the Raven's Progressive Matrices with some Nigerian children. Educ Psychol Meas. 1978;38:465-467.

26. Oyedeji GA. Socioeconomic and cultural background of hospitalized children in Ilesa. Nig J Paediatr. 1985;12:111-117.

27. SPSS Inc. Statistical Package for the Social Sciences. Release 16.0.1. Chicago, IL: SPSS Inc; 2007.

28. Raven J. The Raven's Progressive Matrices: change and stability over culture and time. Cogn Psychol. 2000;41:1-48.

29. Bloom BS. Stability and Change in Human Characteristics. New York, NY: Wiley; 1964.

30. Hunt JM. Intelligence and Experience. New York, NY: Ronald Press Company; 1961.

31. Bradley R, Corwyn R, McAdoo H, Garcia Coll C. The home environments of children in the United States. Part 1: variations by age, ethnicity and poverty status. Child Dev. 2001;72:1844-1867.

32. Magnuson K. Maternal education and children's academic achievement during middle childhood. Dev Psychol. 2000;43:1497-1512.

33. Bartels M, van Beijsterveldt C, Boomsma D. Breastfeeding, maternal education and cognitive function: a prospective study in twins. Behav Genet. 2009;39:616-622. 
HIV/AIDS - Research and Palliative Care

\section{Dovepress}

\section{Publish your work in this journal}

HIV/AIDS - Research and Palliative Care is an international, peerreviewed open-access journal focusing on advances in research in HIV, its clinical progression and management options including antiviral treatment, palliative care and public healthcare policies to control viral spread. The journal welcomes original research, basic science,

clinical \& epidemiological studies, reviews \& evaluations, expert opinion \& commentary, case reports \& extended reports. The manuscript management system is completely online and includes a very quick and fair peer-review system. Visit http://www.dovepress.com/ testimonials.php to read real quotes from published authors.

Submit your manuscript here: http://www.dovepress.com/hivaids---research-and-palliative-care-journal 